\title{
OP11
}

\section{WHICH METRICS ARE NEEDED TO SPECIFY GOOD LIGHTING FOR PEDESTRIANS? \\ Steve Fotios}

DOI 10.25039/x46.2019.OP11

from

CIE x046:2019

Proceedings

of the

29th CIE SESSION

Washington D.C., USA, June 14 - 22, 2019

(DOI 10.25039/x46.2019)

The paper has been presented at the 29th CIE Session, Washington D.C., USA, June 14-22, 2019. It has not been peer-reviewed by CIE.

(C) CIE 2019

All rights reserved. Unless otherwise specified, no part of this publication may be reproduced or utilized in any form or by any means, electronic or mechanical, including photocopying and microfilm, without permission in writing from CIE Central Bureau at the address below. Any mention of organizations or products does not imply endorsement by the CIE.

This paper is made available open access for individual use. However, in all other cases all rights are reserved unless explicit permission is sought from and given by the CIE.

CIE Central Bureau

Babenbergerstrasse 9

A-1010 Vienna

Austria

Tel.: +4317143187

e-mail: ciecb@cie.co.at

www.cie.co.at 


\title{
WHICH METRICS ARE NEEDED TO SPECIFY GOOD LIGHTING FOR PEDESTRIANS?
}

\author{
Fotios, $\mathbf{S}$. \\ University of Sheffield, Sheffield, UNITED KINGDOM \\ Steve.fotios@sheffield.ac.uk
}

DOI 10.25039/x46.2019.OP11

\begin{abstract}
For pedestrian lighting, CIE115:2010 specifies six classes of average and minimum horizontal illuminance (the $\mathrm{P}$ classes) with less specific proposals to consider colour rendering index and semi-cylindrical illuminance if there is a need to recognise pedestrians. This article is a discussion of design metrics: are these appropriate recommendations?
\end{abstract}

Keywords: Pedestrians, design metrics

\section{Background}

In lighting design criteria, numbers should not be the only design target but they often are. Holistic design is a luxury not permitted to all, in particular those designers who are not given sufficient time by their employment situation.

With an assumption that numbers matter, the authors of design guidance have a responsibility to ensure that those numbers are as good as can be. 'Numbers' here means both the metrics employed and the values recommended for those metrics. 'As good as can be' means that guidance decisions (the choices of metrics and numbers) were based on credible empirical evidence (whether practical experience or fundamental research) rather than the opinion of the committee member with the loudest voice or a manufacturer looking to promote their latest products. There is some doubt over the criteria currently recommended (Fotios and Gibbons, 2018).

This article presents some comments on the design criteria for road lighting for pedestrians as presented in CIE115:2010.

\section{How much light?}

CIE115:2010 recommends six classes of lighting for pedestrians, the P classes. The primary metric in these is horizontal illuminance. Illuminance is a measure of the luminous flux per unit area incident on a surface, this being the horizontal road surface for pedestrian lighting. The eye sees the light reflected from the surface rather than the light incident upon the surface and thus luminance would be a more appropriate measure but this requires knowledge of the surface reflectance and hence the direction of view and the characteristics of the observed surface. For driving, the tendency to look straight ahead (Winter et al, 2017) towards a road surface of reasonably well-known reflectance properties, this is a more straightforward situation and luminance-based lighting design can be used. The gaze behaviour of pedestrians is more varied as is the range of surfaces observed which confounds a luminance-based approach: design by illuminance is the convenient alternative.

\section{Where should we measure 'how much'?}

In addition to horizontal illuminance CIE115:2010 also gives minimum vertical and semicylindrical illuminances, suggesting that these are further requirements if facial recognition is necessary.

This focus on facial recognition raises a number of questions. First, how does a designer determine whether or not facial recognition is necessary? The $P$ classes are used where pedestrians are expected to be the dominant road user, implying a likelihood for one pedestrian 
to encounter another facial recognition must therefore be a requirement in all situations where the $\mathrm{P}$ class is used. Eye tracking has demonstrated a tendency to look towards other people when present [Fotios et al, 2015a, 2015b]. Second, facial recognition may not be the right focus. Faces are easily recognised even under conditions which lead to significant image distortion. What may be more appropriate is to evaluate the intentions of other people, whether they are likely to be friendly or threatening, and for this facial emotion recognition has been proposed, operationalised in experimental work as the ability to discriminate between facial expressions (Fotios and Johansson, 2019).

Given the need to see faces of other people, some illuminance on the vertical plane at face height is necessary. The broad spatial distribution typical of sodium and metal halide lamps meant it was reasonable to assume a satisfactory vertical plane illuminance would be available when using these lamps. The more recent desire to limit spatial distribution from a lantern (to reduce sky glow and light pollution) and the more precise optical control of LED lighting means that assumption is no longer reliable. Past studies suggested a good correlation between the cylindrical and horizontal illuminances (Boyce et al, 2000), between horizontal, hemispherical and semi-cylindrical (Fotios et al, 2018). More recent comparisons suggest this is not the case when using LEDs (Table 1).

Table 1 - Caption of Table 1

\begin{tabular}{|c|c|c|c|c|c|}
\hline \multirow[t]{2}{*}{ Year } & \multirow{2}{*}{$\begin{array}{l}\text { Dominant } \\
\text { light } \\
\text { source in } \\
\text { surveyed } \\
\text { roads }\end{array}$} & \multirow[t]{2}{*}{$\begin{array}{l}\text { Number } \\
\text { of roads }\end{array}$} & \multicolumn{3}{|c|}{$\begin{array}{l}\text { Degree of correlation }\left(r^{2}\right) \text { between illuminance } \\
\text { measurements }\end{array}$} \\
\hline & & & $\begin{array}{l}\text { Horizontal vs. } \\
\text { hemispherical }\end{array}$ & $\begin{array}{l}\text { Horizontal vs } \\
\text { semi-cylindrical }\end{array}$ & $\begin{array}{l}\text { Hemispherical } \\
\text { vs. semi- } \\
\text { cylindrical }\end{array}$ \\
\hline $2017^{*}$ & $\mathrm{HPS}^{* *}$ & 9 & $0,95(n=180)$ & $0,87(n=180)$ & $0,96(n=180)$ \\
\hline 2018 & LED & 16 & $0,60(n=320)$ & $0,29(n=320)$ & $0,41(n=320)$ \\
\hline
\end{tabular}

NOTE *As reported in Fotios et al, 2018.

**HPS in six roads, MH in one, florescent in one, LED in two.

A desire to illuminate vertical surfaces to reveal faces does not mean that horizontal illuminances should be ignored. The degree to which vertical or horizontal illuminances dominate design criteria depends in part on the relative importance of the tasks they enhance - interpersonal evaluations and trip hazard detection respectively

It might now be necessary to target a minimum illuminance on the vertical plane in addition to the horizontal. Two candidate measures are vertical illuminance and semi-cylindrical illuminance. Vertical illuminance enables use of the same photometers as for horizontal illuminance and might be considered the more convenient to employ. Semi-cylindrical illuminance measures illuminance on a cylindrical plane: because faces are approximately cylindrical, there have been assumptions that it would better characterise facial evaluations. While a couple of articles have examined the use of semi-cylindrical illuminance (Caminada and van Bommel, 1984, Rombauts et al, 1989) they did not provide a fair comparison against alternative measures (Fotios, 2017a).

CIE115:2010 proposes, for each class, a single value of semi-cylindrical illuminance. This offers no benefit over a single value of vertical illuminance because that single value says nothing about the relative amounts of light in different directions.

A further issue, relevant to both semi-cylindrical illuminance and vertical illuminance, is that a viewing direction needs to be specified. It is currently assumed that the measurement is normal to the direction of view of the pedestrian walking and looking longitudinally along the footpath. This assumption is yet to be tested.

\section{Uniformity of illuminance}

Horizontal illuminances vary across the measurement area according to distance from the sources of light and the optical characteristics of the light source.

There are different approaches to establishing the central tendency (or, average) of a set of data, commonly the mean or median. The mean is widely used but that assumption has yet to 
be tested: if the individual illuminance measurements are not normally distributed then the median average should be used.

In addition to the average a second value is required to characterise the degree of departure from the average. In the P-classes, CIE115:2010 specifies a minimum horizontal illuminance along with the average. The M-classes specify minimum uniformity rather than the minimum luminance. Uniformity of illuminance is ratio of minimum to average illuminance: while not defined directly in the P-classes it is implied by the given minimum and average illuminances.

The uniformity is 0,2 for every P-class which suggests a decision was made that a consistent uniformity across classes is necessary, but that may not be correct. Minimum illuminance and uniformity might require specific minima which could lead to variations in uniformity across the $P$ classes. For example, recent studies have suggested a minimum horizontal illuminance of 1,0 lux for obstacle detection (Fotios and Uttley, 2018): for the currently specified averages this implies uniformities of 0,33 and 0,5 in classes P5 and P6 respectively. Both uniformity and minimum illuminance should be independently specified.

A recent field study used the day-dark approach (Boyce et al, 2000) to investigate reassurance in ten residential roads (Fotios et al, 2018). The results suggested that uniformity gave a better explanation of reassurance evaluations $\left(r^{2}=0,71\right)$ than did mean horizontal illuminance $\left(r^{2}=0,56\right)$, and minimum horizontal illuminance was better than both $\left(r^{2}=0,79\right)$. If validated by further field studies, this would suggest mean illuminance is not the right metric for characterising lighting in residential roads.

\section{Lamp spectrum}

With the advent of LEDs, myriad light spectra are available to the designer, with each spectrum offering variations in correlated colour temperature (CCT), object colour rendition (such as the $\mathrm{CIE}$ general colour rendering index, $\mathrm{Ra}$ ) and S/P ratio. Whether variations in these parameters are of significance depends on the task being performed and the adaptation level. Key visual needs in pedestrian areas are the feeling of reassurance, the detection of hazards, the ability for drivers to detect pedestrians, and evaluating other people.

Detection rate (and similarly, reaction time to detection) can be characterised using the S/P ratio - the ratio of scotopic luminance to photopic luminance (CIE 191:2010). The detection of peripheral trip hazards is enhanced by using lighting of higher S/P ratio, but only at low photopic illuminances, around 0,2 lux (Fotios and Cheal, 2009) or around 0,63 lux (Uttley et al, 2017). At 2,0 lux and above any effect of variation in S/P ratio is negligible. Clearly, light level and light spectrum are interrelated and one must be chosen with consideration to the other.

There is some evidence that the ability of drivers to detect pedestrians may also be enhanced using lighting of higher S/P ratio (Akashi et al, 2007, Lewis, 1999). Further research is needed to show how this varies with light level.

CIE115:2010 states that "high colour rendering contributes to a better facial recognition". The majority of studies, and specifically those submitted to peer-review publication, have not found evidence that facial expression (or facial identity) recognition is affected by changes in lamp spectrum (Boyce and Rea, 1990, Rea et al, 2009, Fotios et al, 2015c, Fotios et al, 2017, Yang and Fotios, 2015). That may not be surprising given that it is a foveal task.

Finally, consider reassurance. The effect of changes in SPD on reassurance is yet to be evaluated. However, spatial brightness is considered to be a reasonable proxy for reassurance (Rea et al, 2009) and for spatial brightness there is evidence that higher content in the short wavelength region enhances spatial brightness. What is not yet known is the how this effect should be characterised, whether by the S/P ratio (Fotios and Cheal, 2011) or some combination of the s-cone and ipRGC responses (Besenecker and Bullough, 2017). That decision needs to consider the robustness of the prediction and practical convenience.

In summary, there may be a benefit to using lighting of higher S/P ratio. This, however, should not be a prompt to using ever higher S/P ratios at the expense of other colour metrics. In BS5489-1:2013 this was addressed by requiring a colour rendering index of $R a \geq 60$ when employing high S/P ratio to permit a reduced average illuminance (Fotios and Goodman, 2012); 
this was a matter of convenience (consistency with the previous version of the standard) - there was no suggestion that $R a=60$ is in any way optimal or that $R a$ is the most appropriate metric.

One further design concern is the pleasantness of the lit environment and there have been investigations seeking to use CCT to optimise evaluations of pleasantness. This is not a straightforward relationship. Following exposure to a particular spectrum we gradually (Fairchild and Reniff, 1995) become chromatically adapted to that spectrum, and a recent review (at photopic levels) did not find evidence that CCT affects pleasantness (Fotios, 2017b). On first exposure to road lighting, the colour appearance of that lighting varies according to the spectrum to which the observer was previously adapted. This is difficult to predict and, probably, outwith the control of the road lighting designer.

There is a common assumption that higher S/P ratio requires a higher CCT. That is however only a rough relationship. A comparison of the S/P ratios and CCT of 297 spectra suggested that while there is a degree of association $\left(r^{2}=0,65\right)$ it is possible to vary S/P ratio at a specific CCT, in particular when a change in lamp technology is possible (Fotios and Yao, 2018).

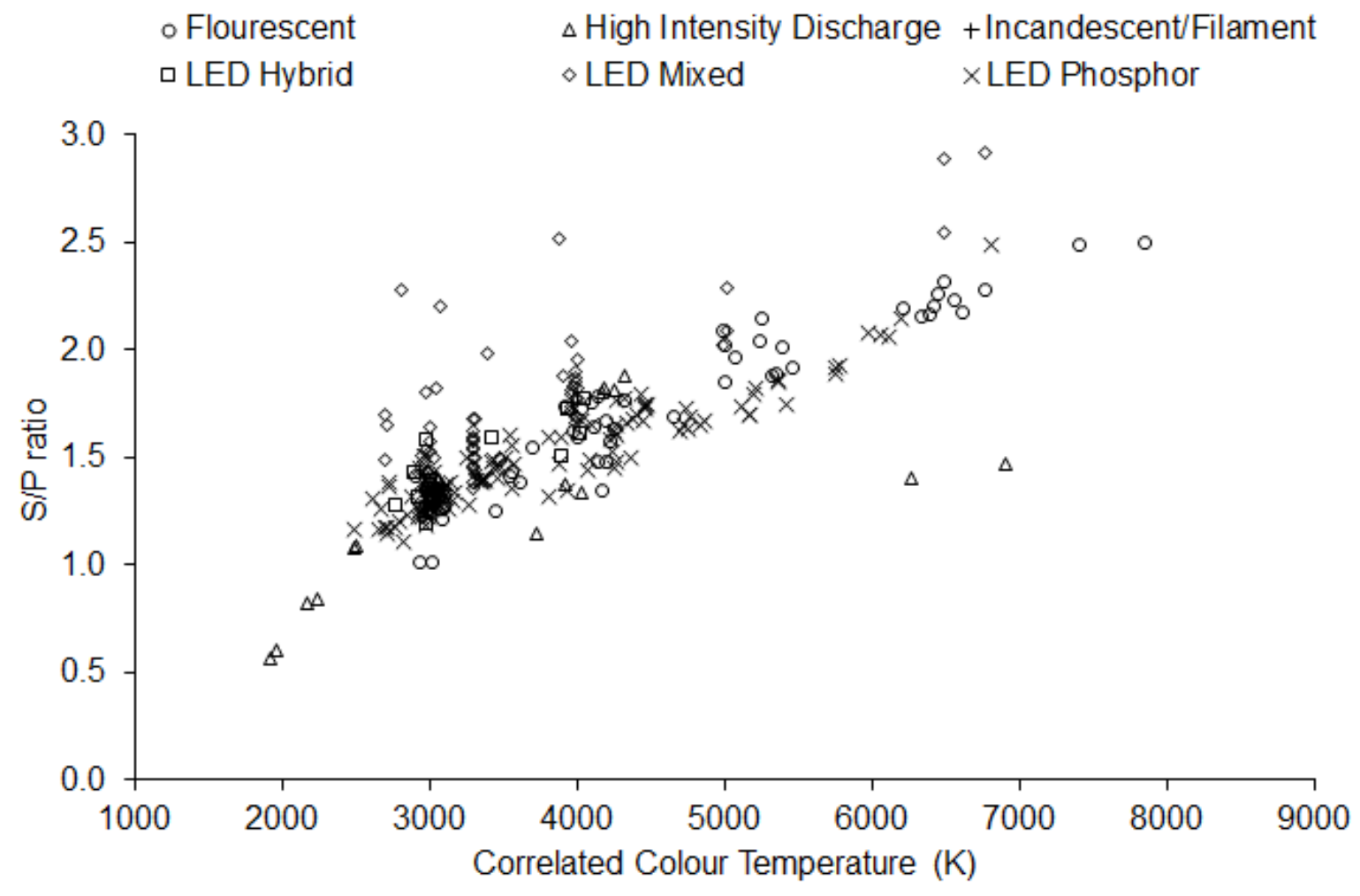

Figure 1 - S/P ratio plotted against CCT for 297 lamp spectra (Fotios and Yao, 2018)

\section{Indirect effects of lighting}

There is some evidence that ambient light influences pedestrian numbers and road traffic collisions involving pedestrians, with increased pedestrian flow (Uttley and Fotios, 2017a, Fotios et al, 2018) and reduced pedestrians RTCs (Elvik, 1995, Uttley and Fotios, 2017b) at higher levels of ambient light. However, this field of research has yet to propose an optimal amount or spectrum of lighting and has yet to propose where and how the amount and spectrum should be measured. It should also be noted that lighting is not the only contributing factor to RTCs and a focus on road lighting by highways engineers may give false confidence of countering accidents and incorrect allocation of funds (Fotios and Price, 2017).

Outdoor lighting may have detrimental effects on the natural environment - wildlife and plant life. There is as yet no consensus as to the magnitude of any detrimental effect, of the tradeoff against safety benefits to pedestrians, and how the detrimental effects are best characterised. 


\section{Proposal}

Lighting design metrics should be chosen so that they characterise the intended benefits of lighting. To characterise the detection of pavement surface trip hazards, minimum horizontal illuminance is needed. To characterise reassurance, uniformity and minimum horizontal illuminance may better predict the degree of reassurance than average horizontal illuminance: taken with obstacle detection, this suggests that CIE115:2010 should specify minimum illuminance and uniformity, not average illuminance. To characterise the ability to evaluate other people vertical illuminance is required: it can be measured with a conventional meter and there is no evidence that semi-cylindrical illuminance is better. Regarding lamp spectrum, an increase in short wavelength radiation enhances detection of peripheral hazards and reassurance. This can be characterised by S/P ratio but there are two caveats: (1) there may be better metrics than S/P ratio, and (2) there is a need to guard against targeting a high S/P ratio at the expense of radiation in the long wavelength region.

\section{Funding}

This work was carried out with support from the Engineering and Physical Sciences Research Council (EPSRC) grant number EP/M02900X/1.

\section{References}

AKASHI, Y., REA, M.S., BULLOUGH, J.D. 2007. Driver decision making in response to peripheral moving targets under mesopic light levels. Lighting Res. Technol., 39, 53-67.

BESENECKER, U.C., BULLOUGH, J.D. 2017. Investigating visual mechanisms underlying scene brightness. Lighting Res. Technol., 49(1), 16-32.

BOYCE, P.R., EKLUND, N.H., HAMILTON, B.J., BRUNO, L.D. 2000. Perceptions of safety at night in different lighting conditions. Lighting Res. Technol., 32(2), 79-91

BOYCE, P.R., REA, M.S. 1990. Security lighting, effects of illuminance and light source on the capabilities of guards and intruders. Lighting Res. Technol., 22, 57-79.

CAMINADA, J.F., VAN BOMMEL, W.J.M. 1984. New lighting criteria for residential areas. J. Illum. Eng. Soc., 13(4), 350-358.

CIE 2010. CIE 115,2010. Lighting of Roads for Motor and Pedestrian Traffic. CIE 115:2010. Vienna: CIE.

CIE 2010. CIE 191:2010. Recommended System for Mesopic Photometry Based on Visual Performance. Vienna: CIE

ELVIK, R. 1995. Meta-analysis of evaluations of public lighting as accident countermeasure. Transport. Res. Rec., 1485(112-123), 11.

FAIRCHILD, M.D., RENIFF, L. 1995. Time course of chromatic adaptation for color-appearance judgements. J. Opt. Soc. Am. A. 12, 824-833.

FOTIOS, S. 2017a. Measure for Measure: Semi-cylindrical illuminance: a semi-conceived measure? Lighting Journal, 82(2), 34-35.

FOTIOS, S. 2017b. A revised Kruithof graph based on empirical data. Leukos, 13(1), 3-17.

FOTIOS, S., CASTLETON, H., CHEAL, C., YANG, B. 2017. Investigating the chromatic contribution to recognition of facial expression. Lighting Res. Technol., 49(2), 243-258.

FOTIOS, S.A., CHEAL, C. 2011. Predicting Lamp Spectrum Effects At Mesopic Levels. Part 1: Spatial Brightness, Lighting Res. Technol., 43(2), 143-157.

FOTIOS, S.A., CHEAL, C. 2009. Obstacle detection: A pilot study investigating the effects of lamp type, illuminance and age. Lighting Res. Technol., 41(4), 321-342.

FOTIOS, S., GIBBONS, R. 2018. Road lighting research for drivers and pedestrians: The basis of luminance and illuminance recommendations. Lighting Res. Technol., 50(1), 154-186. 
FOTIOS, S., GOODMAN, T. 2012. Proposed UK guidance for lighting in residential roads. Lighting Res. Technol., 44(1), 69-83.

FOTIOS, S., JOHANSSON, M. 2019. Appraising the intention of other people: Ecological validity and procedures for investigating effects of lighting for pedestrians. Lighting Res. Technol., 51(1), 111-130.

FOTIOS, S., LIACHENKO MONTEIRO, A., UTTLEY, J. 2018. Evaluation of pedestrian reassurance gained by higher illuminances in residential streets using the day-dark approach. Lighting Res. Technol., Online First 14/05/2018. DOI $10.1177 / 1477153518775464$.

FOTIOS, S., PRICE, T. 2017. Road lighting and accidents: Why lighting is not the only answer. Lighting Journal, 82(5), 22-26.

FOTIOS, S., UTTLEY, J. 2018. Illuminance required to detect a pavement obstacle of critical size. Lighting Res. Technol., 50(3), 390-404.

FOTIOS, S., UTTLEY, J., YANG, B. 2015a. Using eye-tracking to identify pedestrians' critical visual tasks. Part 2. Fixation on pedestrians. Lighting Res. Technol., 47(2), 149-160.

FOTIOS, S., UTTLEY, J., CHEAL, C., HARA, N. 2015b. Using eye-tracking to identify pedestrians' critical visual tasks. Part 1. Dual task approach. Lighting Res. Technol., 47(2), 133-148.

FOTIOS, S., YANG, B., CHEAL, C. 2015c. Effects of Outdoor Lighting on Judgements of Emotion and Gaze Direction. Lighting Res. Technol., 47(3), 301-315.

FOTIOS, S., YAO, Q. 2018. The association between correlated colour temperature and scotopic/photopic ratio. Lighting Res. Technol., Online First 03/07/2018. doi.org/10.1177/1477153518779637

LEWIS, A.L. 1999. Visual performance as a function of spectral power distribution of light sources at luminances used for general outdoor lighting. J. Illum. Eng. Soc., 28, 37-42.

REA, M.S., BULLOUGH, J.D., AKASHI, Y. 2009. Several views of metal halide and high pressure sodium lighting for outdoor applications. Lighting Res. Technol., 41(4), 297-314.

ROMBAUTS, P., VANDEWYNGAERDE, H., MAGGETTO, G. 1989. Minimum semicylindrical illuminance and modelling in residential area lighting. Lighting Res. Technol., 21, 49-55.

UTTLEY, J., FOTIOS, S. 2017a. Using the daylight savings clock change to show ambient light conditions significantly influence active travel. J Environ. Psychol., 53, 1-10.

UTTLEY, J., FOTIOS, S. 2017b. The effect of ambient light condition on road traffic collisions involving pedestrians on pedestrian crossings. Accident Anal. Prev., 108, 189-200.

UTTLEY, J., FOTIOS, S., CHEAL, C. 2017. Effect of illuminance and spectrum on peripheral obstacle detection by pedestrians. Lighting Res. Technol., 49(2), 211-227.

WINTER, J., FOTIOS, S., VÖLKER, S. 2017. Gaze direction when driving after dark on main and residential roads: Where is the dominant location? Lighting Res. Technol., 49(5), 574585.

YANG, B., FOTIOS, S. 2015. Lighting and Recognition of Emotion Conveyed by Facial Expressions. Lighting Res. Technol., 47(8), 964-975. 